\title{
CONFLITO E COOPERAÇÃO NA BACIA DO PRATA: OS INTERESSES E CONTEXTOS POLÍTICOS COMO BASE PARA A (IN)EFETIVIDADE DE UM REGIME INTERNACIONAL ${ }^{* *}$
}

\author{
CONFLICT AND COOPERATION IN THE PLATA BASIN: THE INTERESTS \\ AND POLITICAL CONTEXTS AS BASIS FOR THE (IN)EFFECTIVENESS OF \\ AN INTERNATIONAL REGIME
}

\author{
Armando Gallo Yahn Filho ${ }^{(* *)}$ \\ Universidade Federal de Uberlândia, Uberlândia (MG), Brasil
}

\begin{abstract}
Resumo: Este trabalho tem por objetivo fazer uma análise das relações internacionais na Bacia do Prata, no que tange ao seu aproveitamento hídrico, analisando a (in)efetividade do Tratado da Bacia do Prata. Se, por um lado, as relações hostis entre Brasil e Argentina, decorrentes da incompatibilidade de seus projetos de aproveitamento hidrelétrico do Rio Paraná, nas décadas de 1960 e 1970, caracterizam uma fase predominantemente realista na Bacia do Prata, por outro, o projeto da Hidrovia Paraguai-Paraná, iniciado nos anos 1980, representa a tentativa de afirmação de uma tendência multilateralista das relações internacionais na região, fundamentada na teoria da interdependência complexa.
\end{abstract}

Palavras-chave: Bacia do Prata; Relações Internacionais; Regime Internacional.

Abstract: This work aims to make an analysis of the international relations inthePlataRiver Basin, analyzingthe (in)effectivenessofthePlata Basin Treaty. If, one hand, the hostile relations between Brazil and Argentina, resulting from the incompatibility of their projects for hydroelectricityin the Paraná River, during the decades of 1960 and 1970, features a predominantly realistic phase in the Plata Basin, on the other the Paraguay-Paraná Waterway's project, whichwasstarted in 1980, representsan attempt to claim a multilateral trend for the international relations in the region, based on the theoryofcomplexinterdependence.

Keywords: Plata Basin; International Relations; International Regime.

(*) Este artigo está inspirado em um trabalho de mesma e única autoria, apresentado no III Encontro da Associação Nacional de Pós-graduação e Pesquisa em Ambiente e Sociedade (ANPPAS), realizado em 2006, na cidade de Brasilia-DF.

$(* *)$ Doutor, Professor do Instituto de Economia da Universidade Federal de Uberlândia (UFU); Pesquisador do Núcleo de Estudos e Pesquisa em Relações Internacionais da Universidade Federal de Uberlândia (UFU). E-mail: <agyahn@ gmail.com>. Recebido em: 21.03.2014, aceito em: 02.10.2014. 


\section{INTRODUÇÃO}

A Bacia do Rio da Prata tem uma área de 3,1 milhões de $\mathrm{km}^{2}$, equivalente a 17\% da superfície da América do Sul, sendo a segunda maior bacia deste Continente (a primeira é a Amazônica, com quase 7 milhões de km²) (CIC, 2004).

Este sistema hidrográfico abrange os territórios de cinco países: Argentina, Bolívia, Brasil, Paraguai e Uruguai. A maior parte da área da Bacia se encontra no Brasil $\left(1.415 .000 \mathrm{~km}^{2}\right)$, seguida por Argentina $\left(920.000 \mathrm{~km}^{2}\right)$, Paraguai $\left(410.000 \mathrm{~km}^{2}\right)$, Bolívia $\left(205.000 \mathrm{~km}^{2}\right)$ e Uruguai $\left(150.000 \mathrm{~km}^{2}\right)$. O Paraguai é o único dos cinco países que tem todo seu território inserido na Bacia (CIC, 2004).

O principal rio da Bacia do Prata é o Paraná, com 3.780 km, acompanhado de seus maiores afluentes: o Paraguai, com 2.620 km, e o Uruguai, com 1.600 km. O Rio Paraná se torna Rio da Prata ao receber o Rio Uruguai, pouco antes de desembocar no Oceano Atlântico (ANA, 2001, p. 5).

Outros importantes rios da Bacia do Prata são o Bermejo, o Pilcomaio e o Salado, que, juntamente com o Rio Paraguai, formam a vertente ocidental da Bacia (FONSECA, 1997).

A importância econômica da Bacia do Prata reside no fato de que 70\% do PIB dos cinco países é gerado na Bacia, onde habita cerca de $50 \%$ da população dos mesmos (ANA, 2001, p. 5).

O potencial hidrelétrico da Bacia é de 60 a 70 milhões de $\mathrm{kW}$ e seus principais rios e afluentes proporcionam 15 mil quilômetros de vias navegáveis, constituindo a única saída natural para o mar para Bolívia e Paraguai, pelo Oceano Atlântico, bem como para importantes regiões do Brasil e da Argentina (SCHILLING, 1981, p. 122).

Portanto, por se tratar de uma bacia hidrográfica com potencial econômico diversificado, ela acaba gerando uma disputa pela água não somente dentro dos territórios nacionais, mas também na esfera internacional, sendo a água um recurso estratégico, seja para geração energética, abastecimento industrial, irrigação, transporte e, é claro, consumo humano.

\section{A DISPUTA ENTRE BRASIL E ARGENTINA PELO APROVEITAMENTO DOS RIOS INTERNACIONAIS DA BACIA DO PRATA}

\subsection{AS ORIGENS DO APROVEITAMENTO HIDRELÉTRICO DO RIO PARANÁ}

No início da década de 1960, o Brasil iniciou estudos para o aproveitamento hidrelétrico do Rio Paraná, no seu trecho contíguo entre Brasil e Paraguai. Estudos da época sugeriam o desvio das águas do rio, desde Guaíra, correndo por $60 \mathrm{~km}$ à esquerda do leito primitivo. Como se já não bastasse ser esta região motivo de descontentamento por parte dos paraguaios que, desde o Tratado de Limites, de 1872, não consideravam a demarcação da fronteira como totalmente definida, a iniciativa brasileira de fazer uso exclusivo do rio, desconsiderando-se o regime de condomínio das suas águas, parecia-lhes atentar contra sua soberania (PEREIRA, 1974, p. 51). 
Ao assumir o poder, João Goulart, preocupado com a crise de energia que estava prestes a eclodir, encontrou-se com Stroessner, em Mato Grosso, e combinaram que qualquer aproveitamento do Rio Paraná seria feito mediante mútuo entendimento (PEREIRA, 1974, p. 58).

Contudo, o fim antecipado do mandato de Goulart e a chegada dos militares ao poder, em 31 de março de 1964, mudaram o andamento das conversas. O engenheiro Otávio Marcondes Ferraz, que sempre se posicionou contra a construção de Sete Quedas e defendia o desvio do Rio Paraná, a fim de que o aproveitamento de suas águas fosse feito exclusivamente em território brasileiro, tornou-se presidente da Eletrobras.

A ideia do desvio do rio continuou causando transtornos para a diplomacia brasileira até que, em 1966, o chanceler brasileiro Juracy Magalhães mandou divulgar em Assunção que o Brasil estaria disposto a dar participação de 50\% ao Paraguai, num futuro aproveitamento hidrelétrico dos Saltos de Guaíra (Sete Quedas), o que foi considerado, em Assunção, como um progresso apreciável para a solução das divergências (PEREIRA, 1974, p. 66).

Toda essa manobra diplomática, que se estendeu de 1962 a 1966, era acompanhada pelo Governo argentino com muita preocupação, haja vista ser a Argentina um ribeirinho de jusante, com grandes interesses no potencial hidrelétrico do Rio Paraná. Assim, independentemente de ser um projeto exclusivamente brasileiro ou binacional, com ou sem desvio de águas, a preocupação não deixava de ser a mesma. Qualquer aproveitamento hidrelétrico exigiria a construção de uma barragem no Rio Paraná, que diminuiria o volume de água a jusante.

E, aqui, ressaltamos o conceito de interdependência hidrológica, de Arun Elhance, segundo o qual o compartilhamento de águas internacionais caracteriza uma relação de interdependência entre os países ribeirinhos, na medida em que a ação de um deles pode comprometer os interesses dos demais (ELHANCE, 1999, p. 13).

Outro conceito que se aplica ao caso é o de vulnerabilidade, que pode ser compreendido como a capacidade de reação de um Estado, considerando-se a disponibilidade e a dispendiosidade das alternativas que os atores possuem (KEOHANE; NYE, 1989, p. 12).

Ora, as alternativas da Argentina com relação ao aproveitamento hidrelétrico são muito menores do que as brasileiras, de modo que o potencial energético do Rio Paraná não pode ser tão facilmente substituído por outros rios em território argentino, o que a tornava vulnerável às pretensões brasileiras.

Assim, a fim de amarrar o Brasil a compromissos jurídicos, limitando suas ações na Bacia do Prata, o presidente argentino Arturo Illia (1963-1966) propõe aos países platinos a criação de vínculos para a integração física da Bacia do Prata e o aproveitamento de seus recursos naturais, sob o pretexto de um desenvolvimento regional.

\subsection{A ATA DE IGUAÇU}

Entre as diversas negociações bilaterais preparatórias para a reunião de Chanceleres, convocada pelo Governo argentino, está a Ata de Iguaçu, assinada por Brasil e 
Paraguai, em 22 de junho de 1966, e considerada como o marco inicial que daria origem ao Tratado de Itaipu. Pela Ata de Iguaçu, ou Ata das Cataratas, os Ministros das Relações Exteriores de Brasil e Paraguai:

III. Proclamaram a disposição de seus respectivos governos de proceder, de comum acordo, ao estudo e levantamento das possibilidades econômicas, em particular os recursos hidráulicos pertencentes em condomínio aos dois países do Salto Grande de Sete Quedas ou Salto de Guaíra;

IV. Concordaram em estabelecer, desde já, que a energia elétrica eventualmente produzida pelos desníveis do Rio Paraná, desde e incluisive o Salto Grande de Sete Quedas ou Salto de Guaíra até a foz do Rio Iguaçu, será dividida em partes iguais entre os dois países, sendo reconhecido a cada um deles o direito de preferência para a aquisição desta mesma energia a justo preço que será oportunamente fixado por especialistas dos dois países, de qualquer quantidade que não venha a ser utilizada para o suprimento das necessidades do consumo do outro país;

V. Convieram, ainda, os chanceleres em participar da reunião dos ministros das Relações Exteriores dos Estados ribeirinhos da Bacia do Prata, a realizar-se em Buenos Aires, a convite do Governo argentino, a fim de estudar os problemas comuns da área, com vistas a promover o pleno aproveitamento dos recursos naturais da região e o seu desenvolvimento econômico, em benefício da prosperidade e do bem-estar das populações; bem como a rever e resolver os problemas jurídicos relativos à navegação, balizamento, dragagem, pilotagem e praticagem dos rios pertencentes ao sistema hidrográfico do Prata, à exploração energética dos mesmos, e à canalização, represamento ou captação de suas águas, quer para fins de irrigação, quer para a regularização das respectivas descargas, de proteção das margens ou facilitação do tráfego fluvial; (...) (ATA DO IGUAÇU, 1966)

Por estes dispositivos, percebe-se que Brasil e Paraguai atendem ao convite do Governo argentino para a criação de um grupo da Bacia do Prata, voltado para a cooperação multilateral e o desenvolvimento harmônico da região, ao mesmo tempo que se apressam para resolver o problema do aproveitamento binacional do potencial energético do Rio Paraná, no trecho em que este rio é contíguo aos dois países (BETIOL, 1983, p. 32).

A origem do problema com a Argentina reside, justamente, no item IV da Ata de Iguaçu, que exclui qualquer participação daquele país no projeto, sem qualquer possibilidade de usufruir da energia que seria gerada pela usina a ser construída. Sem uma cooperação com a Argentina, ficaria inviável fazer o aproveitamento completo do potencial existente (PEREIRA, 1974, p. 70).

Além disso, ficam claras as prioridades que os dois países estabelecem na utilização das águas da Bacia do Prata, quais sejam: navegação e geração de energia. Assim, ao Paraguai, o texto da Ata de Iguaçu era duplamente atrativo, pois não só serviria às suas pretensões de obter os lucros advindos do excedente de energia não consumido, como também não excluía a possibilidade de manter uma saída para o mar, superando o problema da mediterraneidade. 


\subsection{AS REUNIÕES DE CHANCELERES DA BACIA DO PRATA}

No dia 27 de janeiro de 1967, em Buenos Aires, realizou-se a Primeira Reunião de Chanceleres da Bacia do Prata, na qual foram definidos os objetivos fundamentais de uma ação conjunta dos países platinos para o desenvolvimento regional, a qual implicava na:

I. vontade de realizar programas de trabalhos multinacionais, bilaterais e nacionais;

II. decisão de criar um Comitê Intergovernamental Coordenador (CIC) encarregado de centralizar as informações e comunicá-las aos governos interessados, e de coordenar a ação conjunta necessária;

III. intenção de instituir em cada país organismos nacionais centralizadores dos estudos e da apreciação dos problemas nacionais relativos à bacia, em colaboração com o CIC (CAUBET, 1989, p. 53-54).

Significativo é o inciso I da Declaração de Buenos Aires, no qual os Chanceleres declaram: "Que é decisão de seus Governos levar a cabo o estudo conjunto e integral da Bacia do Prata, com o fito de realizar um programa de obras multinacionais, bilaterais e nacionais úteis ao progresso da Região."

Este inciso deixa claro que a Argentina não estava querendo inviabilizar os projetos de aproveitamento hídrico na Bacia do Prata, pois também eram de seu interesse, mas preocupava-se em garantir que estes fossem feitos com total participação de todos os Estados ribeirinhos.

Em 1968, realizou-se, em Santa Cruz de la Sierra, na Bolívia, a Segunda Reunião de Chanceleres, que foi assinada a Ata de Santa Cruz de la Sierra, com a qual ficavam delineados os primeiros contornos jurídicos do Sistema da Bacia do Prata. Nesta mesma reunião, aprovou-se o estatuto do Comitê Intergovernamental Coordenador (CIC), que ficou incumbido de preparar um tratado para institucionalizar as relações da Bacia do Prata, a ser apresentado aos Estados-membros na reunião seguinte (CAUBET, 1989, p. 55).

Finalmente, no dia 23 de abril de 1969, durante a III Reunião de Chanceleres, realizada na cidade de Brasília, foi assinado o Tratado da Bacia do Prata, ou Tratado de Brasília, que entrou em vigor em 14 de agosto de 1970, e cujo preâmbulo rezava que " $a$ ação conjugada permitirá o desenvolvimento harmônico e equilibrado, assim como o ótimo aproveitamento dos grandes recursos naturais da região e assegurará sua preservação para as gerações futuras através da utilização racional dos aludidos recursos”.

Com objetivos amplos, explicitados em apenas oito artigos, o Tratado da Bacia do Prata constitui um "acordo-quadro, que vai se complementando na sua regulamentação pelos órgãos institucionais que estabeleceu, embora nenhum deles seja dotado de supranacionalidade" (VILLELA, 1984, p. 154).

Em seu artigo $1^{\circ}$, o Tratado ressalta o "objetivo de promover o desenvolvimento harmônico e a integração física da Bacia do Prata e de suas áreas de influência direta e ponderável" (grifo nosso). Este artigo delimita o espaço físico de aplicação do Tratado. Diferentemente de outros acordos internacionais, que têm aplicabilidade a todo o território, este limita-se à bacia hidrográfica e, portanto, somente a área dos países signatários coberta pela Bacia se submeterá às suas normas (VILLELA, 1984, p. 155). 
Tratava-se, portanto, de reflexo das então recentes Regras de Helsinque (1966) e do conceito de bacia de drenagem internacional, que já influenciavam juristas e diplomatas sul-americanos. Prova disso foi o fato de a legislação argentina já ter, naquela época, incorporado as Regras de Helsinque.

Ainda, no artigo $1^{\circ}$, também em concordância com as Regras de Helsinque, o Parágrafo Único destaca " $a$ utilização racional do recurso água, especialmente através da regularização dos cursos d'água e de seu aproveitamento múltiplo e eqüitativo". Este dispositivo não exclui nenhum tipo de aproveitamento, considerando que a água pode e deve ser utilizada para diversas finalidades, mas deixa claro que nenhum uso pode ser feito em detrimento dos demais países, quer seja em prejuízo da quantidade, quer seja da qualidade da água.

Os redatores do Tratado não dão uma regulamentação muito clara ao órgão máximo ou supremo do Sistema, a fim de evitar uma vida jurídica independente. A Reunião dos Chanceleres passa a ser a instância decisória mais importante do Sistema da Bacia do Prata, sem, contudo, ter qualquer personalidade jurídica (VILLELA, 1984, p. 157).

Como bem sintetiza Villela (1984, p. 162):

(...) o Tratado da Bacia do Prata não criou uma organização, uma associação ou uma entidade supranacional (...), [resumindo-se] a um acordo-quadro, que dá linhas gerais de uma institucionalização, que vai se fazendo e tornando operacional, através de uma série de outros acordos derivados e uma regulamentação complementar, baixada pela Reunião dos Chanceleres, em forma de resoluções.

É preciso que se dê uma explicação com relação ao termo “institucionalização". Ele tem sido utilizado pela literatura com duplo significado, podendo representar:

I. a confirmação de regras a serem seguidas, por meio da implementação de tratados ou órgãos que não necessariamente têm caráter de uma organização, ou nem mesmo são dotados de personalidade jurídica;

II. a constituição de uma organização, no sentido estrito da palavra, com personalidade jurídica. Para fins deste trabalho, a palavra "institucionalização" e seus derivativos se referem à primeira definição acima.

Assim sendo, o Tratado da Bacia do Prata pode ser entendido como um regime internacional, na definição de Mikael Román, segundo a qual um "regime internacional é uma instituição social composta de princípios, normas, regras de procedimento de tomadas de decisão, previamente acordados, que pretendem governar, ou governam, a interação dos atores em áreas temáticas específicas" (ROMÁN, 1998, p. 65).

Esta definição fornece elementos que nos permitem compreender que a efetividade de um regime internacional está desvinculada da sua implementação. Ao acrescentar a expressão "que pretendem governar", este conceito admite, diferentemente dos anteriores, a possibilidade de um regime ser estabelecido, mas não produzir os resultados pretendidos (ROMÁN, 1998, p. 65).

Para Román (1998, p. 64), o componente normativo dos regimes não é suficiente para governar as interações entre os atores, sendo necessário entendê-los como implementação de políticas internacionais, que são previamente negociadas. 
Assim, o autor explica que, no plano internacional, não há um quadro jurídico bem definido, de modo que as negociações tendem a resultar em decisões vagas e não amarradas, sendo que o próprio conceito de soberania impede os Estados de fazerem certas concessões (ROMÁN, 1998, p. 108-109).

No Tratado da Bacia do Prata, restou clara a intenção dos atores de preservar suas soberanias e garantir a liberdade de executar obras de seu interesse, no plano interno, sem preocupação com os possíveis danos transfronteiriços, de forma que estes são os princípios basilares do Tratado e, portanto, do regime. Como consequência, temos um conjunto de normas que se esvaem, tornando a tarefa do jurista extremamente inócua, ao fazer uma interpretação estritamente jurídica deste Tratado.

Paradoxalmente, temos a existência de um regime internacional em meio às relações fundamentadas no realismo político. A cooperação estabelecida pelo elemento normativo do regime foi inibida pela implementação de uma política internacional, previamente negociada, cuja base era a manutenção dos interesses individuais de cada país, em detrimento de um ganho coletivo.

Assim, os resultados pretendidos, procedendo-se à simples leitura dos artigos do Tratado, não são alcançados por uma decisão dos próprios signatários. Decisão esta que não está explícita no texto, mas que se depreende do processo de negociação. Disso decorre que há uma implementação sem, contudo, efetividade.

Caubet (1989, p. 126) descreve a situação de instabilidade das relações platinas com as seguintes palavras:

O fato de as autoridades militares estarem no poder em todos os países da bacia, com raros momentos e exceções, é muito mais fundamental para explicar o estado de crise quase permanente nas relações interestatais regionais. A análise das relações internacionais que prevalece nos meios militares está, com efeito, estreitamente subordinada às concepções geopolíticas do poder; e essas baseiam-se em premissas que privilegiam os aspectos conflitantes das relações.

O fato de a implementação do Tratado da Bacia do Prata não ter sido suficiente para impedir os conflitos que se seguiram a ele, com relação à construção das usinas de Itaipu e Corpus, comprova a validade da teoria de Román sobre regimes internacionais, aplicada a este caso. Vale notar que, para o Brasil, a assinatura deste tratado estava voltada aos seus interesses geopolíticos de prosseguir com o projeto de Itaipu, tentando amenizar as tensões com a Argentina.

\subsection{A ESCOLHA DE ITAIPU}

Depois de estudos realizados no Rio Praraná, chegou-se à conclusão de que o projeto com maior rendimento econômico indicava uma barragem a ser construída em Itaipu, embora Santa Maria, localizada a 13 quilômetros abaixo de Sete Quedas, também oferecesse atrativos (PEREIRA, 1974, p. 119).

Uma solução que poderia representar a otimização do aproveitamento hidrelétrico do Rio Paraná seria o compartilhamento da energia produzida por uma única usina, ao invés da tentativa de se compatibilizar a construção de três barragens (Itaipu, Yaciretá e Corpus). 
Muito se questionam as razões pelas quais o Brasil fez uma opção pela construção de uma usina binacional se o Rio Paraná, em seu trecho exclusivamente brasileiro, poderia gerar a mesma energia com a construção de pequenas hidrelétricas ao longo de seu curso. Para nós, a compreensão deste fato está no entendimento do contexto internacional da disputa brasileiro-argentina pela supremacia do Cone Sul, mais especificamente nas concepções geopolíticas dos governos militares de Argentina e Brasil.

O debate em torno da questão ambiental, que se inicia na década de 1960, agrega novos elementos ao impasse em torno da construção de Itaipu. Se por um lado, a Chancelaria argentina tenta reforçar a tese da consulta prévia, por outro, o Brasil reforça sua posição de defesa do livre aproveitamento dos recursos naturais sob sua soberania e condena o "congelamento do poder mundial" e o "totalitarismo ecológico".

A Argentina viu na Conferência de Estocolmo a chance para inviabilizar a construção de Itaipu, obtendo a aprovação de uma regulamentação internacional sobre o uso de rios internacionais. A tese da Chancelaria argentina estava respaldada no conceito de bacia de drenagem internacional, estabelecido pela International Law Association, em 1966 (GALVÃO, 1996, p. 93).

A tentativa argentina se deu pela apresentação de uma emenda que recolocava o direito à consulta prévia, cabendo às partes interessadas "aquilatar e julgar elas próprias da natureza e dos efeitos" das atividades realizadas. Em contraofensiva, o Brasil apresentou o seguinte princípio alternativo: "Nenhum Estado está obrigado a suprir informação em condições tais que, a seu juízo fundamentado, possa prejudicar sua segurança nacional, o seu desenvolvimento econômico ou os seus esforços para melhoria do meio ambiente."

Assim, em troca de notas entre os Ministros das Relações Exteriores dos dois países, chegou-se a um acordo sobre o exercício da soberania estatal e da sua limitação, na exploração e desenvolvimento de recursos naturais, não tratando, explicitamente, do aproveitamento de águas internacionais, nem muito menos dos aproveitamentos na Bacia do Prata (BETIOL, 1983, p. 114).

Por este acordo, fica estatuído que: "Na exploração e desenvolvimento de seus recursos naturais, os Estados não devem causar efeitos prejudiciais sensíveis em zonas situadas fora de sua jurisdição nacional.” (apud BETIOL, 1983, p. 114.)

O Acordo de Nova York, como ficou conhecido, foi aproveitado na XXVII Sessão da Assembleia Geral da ONU e se tornou a Resolução n. 2.995, aprovada por 115 votos a favor, 10 abstenções e nenhum voto contra.

Contudo, quando o caso concreto demandou a aplicação prática do Acordo de Nova York, os resultados foram frustrantes. O enchimento da represa de Ilha Solteira, em 1973, deveria ser feito com base no referido Acordo, que se tornara, também, norma internacional, pela Resolução n. 2.995 da XXVII Sessão da AGNU. Entretanto, baseando-se no fato de que a Usina de Jupiá estava a jusante de Ilha Solteira e, portanto, qualquer influência do represamento desta seria controlada por aquela, o Ministério das Relações Exteriores brasileiro divulgou a seguinte nota:

A Resolução n. 2.995 (XXVII) da Assembléia Geral das Nações Unidas se destina a casos em que na exploração e no aproveitamento de recursos naturais exista a possibilidade de 
que venha a ocorrer prejuízo sensível fora da jurisdição nacional do Estado que empreenda a obra. Ora, no caso do enchimento de Ilha Solteira, tal possibilidade inexiste por inteiro. (apud PEREIRA, 1974, 169.)

Os protestos da Chancelaria argentina foram imediatos. Afinal, como tínhamos visto, pelo texto do Acordo de Nova York, nem Brasil, nem Argentina seria juiz no caso de controvérsias. E, por esta nota do Itamaraty, o Brasil estava julgando seus próprios atos.

Finalmente, em 26 de abril de 1973, Brasil e Paraguai assinam o Tratado de Itaipu, cujo artigo I estatui:

As altas partes contratantes convêm em realizar em comum e de acordo com o presente Tratado e seus anexos, o aproveitamento hidrelétrico dos recursos hídricos do Rio Paraná, pertencentes em condomínio aos dois países, desde e inclusive o Salto Grande de Sete Quedas ou Salto de Guaíra até a foz do Rio Iguaçu.

O Anexo B do Tratado traz a "descrição geral das instalações destinadas à produção de energia elétrica e das obras auxiliares" e, por este motivo, era o principal objeto da atenção do Governo argentino. Afinal, a definição das cotas de Itaipu poderia inviabilizar a usina de Corpus.

Por este motivo, nele foi incluída a "cláusula peronista", trazida por Stroessner à Brasília, e cujo teor reproduzimos:

As obras descritas no presente anexo poderão sofrer modificações ou adições, inclusive nas suas cotas e medidas, por exigências técnicas que se verificarem durante sua execução. Ademais, se por exigência da mesma natureza ficar demonstrada a necessidade de redução substancial da cota do coroamento da barragem, será considerada a conveniência da execução adicional de outro aproveitamento hidrelétrico a montante conforme previsto no "Relatório Preliminar" supracitado.

Com isto, o Paraguai tentava não impedir a construção de Corpus e o Brasil, de certa forma, mostrava-se conformado com a ideia de que a construção de Itaipu estaria condicionada a futuras negociações com a Argentina (PEREIRA, 1974, p. 229).

Com as sucessivas tensões entre Brasil e Argentina, por conta do aproveitamento hidrelétrico do Rio Paraná, o Chanceler argentino, Juan Carlos Puig, em 10 de julho de 1973, denunciou o Acordo de Nova York, alegando que este não produzira bons frutos (PEREIRA, 1974, p.172).

Segue-se a este fato a disposição do Governo argentino de retomar as discussões a respeito da consulta prévia. Como fruto do comparecimento à reunião de Chefes de Estado dos países não alinhados, em Argel, e da sua decisiva participação nas resoluções em favor do Terceiro Mundo, a Argentina conquistou o apoio necessário para aprovar, na Asembleia Geral das Nações Unidas, em 1973, a Resolução n. 3.129, cujo inciso II estatui:"Estima também que a cooperação entre países interessados na exploração de ditos recursos deve desenvolver-se sobre a base de um sistema de informação e de consultas prévias, no marco das relações normais que existem entre eles." (grifo nosso) 
Apesar de ter sido comemorada como uma vitória pela diplomacia argentina, a Resolução n 3.129, assim como todas as resoluções da ONU, enquadram-se no que se chama de soft law. Isto significa que sua força jurídica se dá no plano moral e da boa convivência entre os Estados, sem qualquer caráter de coerção.

\subsection{O ACORDO TRIPARTITE}

Finalmente, em 19 de outubro de 1979, Brasil, Argentina e Paraguai assinaram o Acordo Tripartite de harmonização das barragens. Assim, "os diversos aspectos das polêmicas do período anterior foram reduzidos a cláusulas jurídicas precisas, que contemplam os direitos e fixam as obrigações das partes” (CAUBET, 2000, p. 131).

Vale ressaltar que o Acordo Tripartite só foi assinado dez anos depois do Tratado da Bacia do Prata. Ou seja, os avanços que, supostamente, o texto do Tratado parecia trazer, no âmbito da cooperação, não foram suficientes para coibir as tensões na região platina, mas somente para não acirrá-las.

Como já vimos, a causa da longa duração da controvérsia entre Brasil e Argentina, mesmo depois da assinatura do Tratado da Bacia do Prata, está na própria natureza do Tratado, que, por configurar um regime internacional, cujos princípios basilares são a soberania dos Estados e a liberdade de executar projetos nos seus próprios territórios, apresenta um baixo grau de institucionalização, tal como desejado pelos próprios países signatários.

\section{A HIDROVIA PARAGUAI-PARANÁ: O CAMINHO PARA COOPERAÇÃO}

Enquanto as décadas de 1960 e 1970 ficaram marcadas pelas relações conflituosas entre Brasil e Argentina, truncando o processo de integração na Bacia do Prata, os anos 1980 e 1990 representaram um avanço significativo na cooperação entre os dois países, que se estendeu, consequentemente, a todos os demais Estados da região.

Sem dúvida, o fato fundamental para a mudança de rumos nas relações argentino-brasileiras foi a assinatura do Acordo Tripartite, em 1979, que colocou fim ao impasse em torno dos projetos de Itaipu e Corpus, para o aproveitamento hidrelétrico do Rio Paraná. Colaboraram, também, os processos de redemocratização em ambos os países, bem como os projetos de integração econômica e comercial, tais como: Programa de Integração e Cooperação Argentina-Brasil (PICAB) e MERCOSUL.

No que diz respeito, especificamente, ao aproveitamento dos recursos hídricos da Bacia do Prata, tema deste trabalho, o principal projeto de cooperação multilateral, que surge na década de 1980, sinalizando para uma efetiva integração da infraestrutura sub-regional, é a Hidrovia Paraguai-Paraná.

Com extensão de $3.442 \mathrm{~km}$, esta via fluvial une os cinco países da Bacia (Argentina, Bolívia, Brasil, Paraguai e Uruguai), tendo como extremidades os portos de Cáceres, no Mato Grosso, e Nova Palmira, no Uruguai. A superfície total da sua área de influência direta é de 1,75 milhões de km², com uma população superior a 17 milhões de habitantes (INTAL, 1991, p. 08). 
Este projeto representa um processo de cooperação caracterizado pelos ganhos múltiplos. Assim sendo, se a análise que fizemos a respeito do diferendo Itaipu-Corpus tinha um caráter predominantemente realista, as relações multilaterais que passaremos a analisar, a partir de agora, conformam uma interdependência complexa, com a ampla participação de setores não estatais, tais como o empresariado, o setor de serviços e as organizações não governamentais de cunho ambiental.

O processo de cooperação econômica e comercial, no âmbito sub-regional, exigia uma integração da infraestrutura. Basta tomarmos o exemplo da Europa para verificarmos como o processo de criação da União Europeia foi sempre acompanhado pelos investimentos em infraestrutura, a fim de ligar todos os países numa rede multimodal, unindo hidrovias, ferrovias e rodovias.

Nas palavras de Sanguinetti (1991, p. 43):

Este, além de ser um projeto de transporte, é, sobretudo, um projeto integrador destes cinco países [da Bacia do Prata] e, talvez, não seria exagerado estabelecer um paralelo entre o que representa o desenvolvimento da Hidrovia [Paraguai-Paraná] e o que foi o desenvolvimento da Comunidade do Carvão e do Aço na Europa, que, sem nenhuma dúvida, foi a semente para a criação do Mercado Comum Europeu.

Como já vimos ao longo deste trabalho, a navegação sempre esteve em pauta nas relações entre os ribeirinhos platinos, haja vista ser o sistema hidrográfico do Prata extremamente propício para o deslocamento de mercadorias, seja com destino ao Atlântico, ou no sentido contrário, penetrando o hinterland sul-americano.

\subsection{A HIDROVIA PARAGUAI-PARANÁ E O TRATADO DA BACIA DO PRATA}

O projeto da Hidrovia Paraguai-Paraná tem sua origem na Declaração de Buenos Aires, resultante da I Reunião de Chanceleres da Bacia do Prata, em 1967, que, em seu inciso IV, A, estabelece:

IV - Que, para atingir os objetivos do desenvolvimento integral da Bacia, o estudo deverá levar em conta, principalmente, os seguintes temas:

A) Facilidades e assistência à navegação; estabelecimento de novos portos fluviais e melhoramento dos já existentes, com o propósito de que possam ser utilizados, de maneira mais eficiente, pelos países da Bacia e, em especial, por aqueles que têm situação mediterrânea; estudos hidrelétricos com vistas à integração energética da Bacia; instalação de serviços de águas para usos domésticos, sanitários e industriais, e para irrigação; controle de cheias e inundações, e da erosão; conservação da vida animal e vegetal.

Como se pode perceber do extrato acima, a preocupação com a mediterraneidade de Bolívia e Paraguai já estava inserida nas primeiras conversas sobre o Sistema da Bacia do Prata, cujo objetivo era criar um marco institucional para o desenvolvimento integrado da Bacia. Como já dissemos, não se pode pensar em uma inserção no comércio internacional sem saídas para o mar, haja vista ainda serem os transportes fluvial e marítimo os mais baratos do mundo. 
Já na II Reunião de Chanceleres, em 1968, quando ficaram definidos os primeiros contornos jurídicos do Sistema da Bacia do Prata, a Ata de Santa Cruz de La Sierra estabeleceu as bases do que mais tarde viria a ser a Hidrovia Paraguai-Paraná:

II - Com referência aos projetos concretos apresentados pelos países-membros, resolvem:

Aprovar a realização dos estudos preliminares à execução dos respectivos projetos:

Projetos compartilhados pelos países-membros:

1) construção de um porto em território boliviano, sobre o Rio Paraguai, e sua conexão com a rede ferroviária (Porto Busch);

(...)

4) estudar os problemas a resolver e projetar as medidas a tomar (dragagem, remoção de obstáculos, sinalização, balizamento, etc.) para permitir a navegação permanente e assegurar sua manutenção nos Rios Paraguai, Paraná, Uruguai e da Prata, especialmente nos trechos de Corumbá - Assunção, Assunção - Confluência, Confluência - Rio da Prata, Salto Grande - Nova Palmira, e prever o sistema mais adequado para a recuperação dos investimentos que forem necessários efetuar e a compensação dos serviços que exijam o cumprimento deste programa; (ATA DA SANTA CRUZ DE LA SIERRA, 1968)

Como já sabemos, na III Reunião de Chanceleres, realizada em Brasília, foi assinado o Tratado da Bacia do Prata, em 23 de abril de 1969, cujo artigo 1ํ, Parágrafo Único, item a, prioriza a facilitação e assistência à navegação.

Contudo, até a assinatura do Acordo Tripartite, em 1979, houve uma "bilateralização" das relações internacionais na Bacia, o que representava um contrassenso ao texto do Tratado de Brasília, cujo teor apontava para o multilateralismo. No que tange aos recursos hídricos, esta "bilateralização" esvaziava o Tratado, na medida em que contrariava um de seus princípios jurídicos fundamentais, qual seja, o aproveitamento conjunto da Bacia (RAVINA, 1991, p. 27).

A partir de 1991, este quadro muda, começando pela Resolução n. 238, da XIX Reunião de Chanceleres, que incorpora o projeto da Hidrovia Paraguai-Paraná ao Sistema da Bacia do Prata.

Em junho de 1992, é Assinado o Acordo de Transporte Fluvial pela Hidrovia Paraguai-Paraná (1997, p. 14-22), cujo preâmbulo faz menção explícita ao Tratado da Bacia do Prata e à Resolução n. 238, da XIX Reunião de Chanceleres.

Uma das maiores preocupações com relação à navegação na Hidrovia Paraguai-Paraná residia no aproveitamento múltiplo da água, tanto no que dizia respeito aos empecilhos que poderiam ser causados à navegação por conta de outros aproveitamentos, quanto às consequências desta para os demais usos d'água.

Em um estudo sobre os aspectos institucionais da hidrovia, Arturo Ravina e sua equipe de consultores já mostravam esta preocupação, numa época em que se discutiam os modelos mais apropriados para o Estatuto do Comitê Intergovernamental da Hidrovia: 
A interação entre a navegação e os outros usos e efeitos das águas de rios internacionais determina a inconveniência de regulamentar juridicamente a navegação separadamente dos demais usos e efeitos. Deste modo, todos os usos e efeitos devem ser normatizados conjuntamente, reconhecendo a assinalada interdependência. (RAVINA, 1991, p. 23.)

E prossegue:

Entre os aspectos institucionais a considerar está, em primeiro lugar, o da concessão de prioridades entre a navegação e os demais usos de um rio internacional. Cabe recordar que as Regras de Helsinque não reconhecem prioridade a nenhum uso. Portanto, o das prioridades é um tema não sujeito a regras "a priori", que deve ser resolvido conforme as circunstâncias particulares de tempo e espaço, por acordo entre os governos interessados. (RAVINA, 1991, p. 23.)

Isto tudo nos remete, novamente, ao conceito de "interdependência hidrológica", de Arun Elhance.

Finalmente, em setembro de 1992, é aprovado, na XX Reunião de Chanceleres, o Estatuto do Comitê Intergovernamental da Hidrovia, pela Resolução n. 244. Por ele, fica definido que o referido Comitê:

(...) é o órgão do Sistema do Tratado da Bacia do Prata encarregado de coordenar, propor, promover, avaliar, definir e executar as ações identificadas pelos Estados-membros, relativas ao Programa da Hidrovia Paraguai-Paraná, bem como gerir e negociar prévia anuência das autoridades nacionais pertinentes de cada país, acordos de cooperação técnica e assinar aqueles para o desenvolvimento de um sistema eficiente de transporte fluvial, constituindo-se no foro de entendimento para assuntos relacionados a este tema.

\section{CONSIDERAÇÕES FINAIS}

Nas décadas de 1960 e 1970, as divergências entre Brasil e Argentina pelo aproveitamento do potencial hidrelétrico do Rio Paraná representaram uma fase realista das relações na Bacia do Prata. O diferendo Itaipu-Corpus levou o Governo argentino a tentar estabelecer um quadro jurídico preciso para o aproveitamento conjunto dos recursos da Bacia, o que culminou na assinatura do Tratado da Bacia do Prata. Porém, sua natureza de regime internacional, tendo como princípios basilares a soberania e a liberdade de cada país em executar obras de seu interesse em território nacional, explica o baixo grau de institucionalização na Bacia e a consequente longevidade da disputa brasileiro-argentina, até a assinatura do Acordo Tripartite, em 1979. Percebe-se, assim, uma inefetividade jurídica do Tratado da Bacia do Prata, na medida em que sua assinatura se justifica não pelo interesse do Governo brasileiro em uma plena cooperação multilateral, mas, sim, pela tentativa em amenizar as tensões com a Argentina até a consolidação do projeto de Itaipu.

Por outro lado, na década de 1980, findo o impasse em torno da construção de Itaipu, e considerando-se o processo de redemocratização no Brasil e na Argentina, somado aos projetos de integração econômica e comercial, abre-se um novo caminho para a cooperação. No que diz respeito aos recursos hídricos, esta nova fase se materializa no 
projeto da Hidrovia Paraguai-Paraná, que resgata o Tratado da Bacia do Prata, dando-lhe uma efetividade jurídica e fortalecendo seu grau de institucionalização. Assim, os princípios basilares deste regime internacional passam a ser a integração regional e a inserção econômica da região no sistema internacional, o que demanda uma integração da infraestrutura sul-americana.

\section{BIBLIOGRAFIA}

\subsection{LIVROS E REVISTAS}

BETIOL, Laércio. Itaipu: modelo avançado de cooperação internacional na Bacia do Prata. Rio de Janeiro: Fundação Getúlio Vargas, 1983.

CAUBET, Christian Guy. As grandes manobras de Itaipu: energia, diplomacia e direito na Bacia do Prata. São Paulo: Acadêmica, 1989.

CAUBET, Christian Guy. A política hidroenergética brasileira e a evolução do quadro diplomático na Bacia do Prata. In: ALBUQUERQUE, José Augusto Guilhon (org.). Sessenta anos de política externa brasileira (1930-1990). v. 03, São Paulo: Annablume/NUPRI-USP, 2000.

ELHANCE, Arun. Hydropolitics in the third world: conflict and cooperation in international rivers. Washington: United States Institute of Peace, 1999.

GALVÃO, Luís Eduardo Barros. Soberania, natureza e segurança nacional: um estudo sobre a política externabrasileira para o meio ambiente. 1996. 190p. (Dissertação de Mestrado). Instituto de Relações Internacionais, Pontifícia Universidade Católica, Rio de Janeiro.

KEOHANE, Robert; NYE, Joseph. Power and Interdependence. 2. ed. Harper Collins Publishers, 1989.

PEREIRA, Osny Duarte. Itaipu: prós e contras. Rio de Janeiro: Paz e Terra, 1974.

RAVINA, Arturo (coord.). La organización institucional de la Hidrovía Paraguay-Paraná como programa de navegación internacional. Integración Latino-americana, INTAL, v. 16, n. 168, p. 21-41, 1991. ROMÁN, Mikael. The implementation of international regimes: the case of the Amazon Cooperation Treaty. Uppsala: Uppsala University, 1998.

SANGUINETTI, Jorge. "Proyecto Hidrovía": oportunidades del empresariado. Integración Latinoamericana, INTAL, v. 16, n. 168, p. 42-51, 1991.

SCHILLING, Paulo R. O expansionismo brasileiro: a geopolítica do General Golbery e a Diplomacia do Itamaraty. São Paulo: Global, 1981.

VILlELA, Anna Maria. O Tratado da Bacia do Prata. Revista de Informação Legislativa. Brasília, v. 21, n. 81, p. 147-176, 1984.

\subsection{DOCUMENTOS}

ACORDO DE TRANSPORTE FLUVIAL PELA HIDROVIA PARAGUAI-PARANÁ, de 23 jun. 1992. In: MERCIER, Antonio Sergio Pacheco (coord.). A navegação fluvial pela Hidrovia Paraguai-Paraná. Osasco: FIEO, 1997.

AGÊNCIA NACIONAL DE ÁGUAS (ANA). Bacias brasileiras do Rio da Prata: avaliações e propostas. Brasília, 2001. Disponível em: <http://www5.prossiga.br/recursoshidricos/pdf/relprata.pdf> Acesso em: 10 ago. 2004.

ATA DE IGUAÇU, 1966. In: BETIOL, Laércio. Itaipu: modelo avançado de cooperação internacional na Bacia do Prata. Rio de Janeiro: Fundação Getúlio Vargas, 1983. 
ATA DE SANTA CRUZ DE LA SIERRA, de 20 de maio de 1968. Revista de Informação Legislativa. Brasília, v. 21, n. 81, p. 621-625, 1984.

COMITÉ INTERGUBERNAMENTAL COORDINADOR DE LOS PAÍSES DE LA CUENCA DEL PLATA (CIC). La Cuenca del Plata: Información General. Buenos Aires, 2004. Disponível em: <http:// www.cicplata.org/?id=lc_infogen\#lcdp> Acesso em: 8 abr. 2005.

DECLARAÇÃO DE BUENOS AIRES, de 27 de fevereiro de 1967. Revista de Informação Legislativa. Brasília, v. 21, n.81, p. 619-621, 1984.

FONSECA, Getúlio Lamartine de Paula. O MERCOSUL e sua rede hidrográfica. Informativo n. 4. Brasília, Congresso Nacional, Comissão Parlamentar Conjunta do MERCOSUL, Representação Brasileira, fev.-mar. 1997. Disponível em: <http://www.camara.gov.br/mercosul/Informativo/ info_4.htm\#Mercosul> Acesso em: 8 abr. 2005.

INSTITUTO PARA A INTEGRAÇÃO DA AMÉRICA LATINA E DO CARIBE (INTAL). Oportunidades empresariales en la Hidrovía Paraguay-Paraná. Integración Latinoamericana, v. 16, n. 168, p. 03-20, 1991.

TRATADO DA BACIA DO PRATA, de 23 abril 1969. Revista de Informação Legislativa. Brasília, v. 21, n. 81, p. 625-628, 1984.

TRATADO DE ITAIPU, de 26 abril 1973. In: PEREIRA, Osny Duarte. Itaipu: prós e contras. Rio de Janeiro: Paz e Terra, 1974. 